CLINICAL STUDY

\title{
Daily insulin requirement of children and adolescents with type 1 diabetes: effect of age, gender, body mass index and mode of therapy
}

\author{
Susanna Wiegand, Klemens Raile, Thomas Reinehr ${ }^{1}$, Sabine Hofer ${ }^{2}$, Andrea Näke ${ }^{3}$, Wolfgang Rabl ${ }^{4}$, Reinhard \\ W Holl ${ }^{5}$ and on behalf of the DPV-Wiss Study Group \\ Department of Pediatric Endocrinology and Diabetology, Charité Children's Hospital, Universitätsmedizin Berlin, Augustenburger Platz 1, 13353 Berlin, \\ Germany, ${ }^{1}$ Department of Pediatric Endocrinology and Diabetology, Vestische Hospital for Children and Adolescents, University of Witten-Herdecke, \\ Datteln, Germany, ${ }^{2}$ Department of Pediatrics, Medical University of Innsbruck, Innsbruck, Austria, ${ }^{3}$ Department of Pediatric Endocrinology and \\ Diabetology, University of Dresden, Dresden, Germany, ${ }^{4}$ Department of Pediatric Endocrinology and Diabetology, TU München, München, Germany and \\ ${ }^{5}$ Department of Epidemiology, University of Ulm, Ulm, Germany \\ (Correspondence should be addressed to S Wiegand; Email: susanna.wiegand@charite.de)
}

\begin{abstract}
Design: The purpose of this study was to generate insulin dose (ID) percentiles for children and adolescents with type 1 diabetes mellitus (DM1) having the opportunity to assess this important parameter in relation to age and sex.

Methods: Daily IDs per weight (ID/kg) were recorded in 22177 patients with DM1 (3-25 years of age, DM1 duration of more than 2 years, $48 \%$ female) and ID percentiles (ID-Perc) were created statistically. The ID-Perc were compared between male and female, and between multiple insulin injection therapy (MIT) and continuous s.c. insulin infusion (CSII). A multivariate regression analysis was performed for ID in the third year of DM1 with ID/kg, body weight, age, gender, and insulin delivery regimen as variables.

Results: The 50th ID-Perc (P50) varied among $0.67 \mathrm{IU} / \mathrm{kg}$ (age 3 years), $0.93 \mathrm{IU} / \mathrm{kg}$ (13 years), and $0.70 \mathrm{IU} / \mathrm{kg}$ (23 years) increasing from early childhood to adolescence and decreasing toward adulthood. Highest P50 ID was found at 12 years in females $(0.94 \mathrm{IU} / \mathrm{kg})$ and at 14 years in males $(0.92 \mathrm{IU} / \mathrm{kg}$ ). Using ICT, the ID was significantly higher compared with CSII (P50: $0.94 \mathrm{IU} / \mathrm{kg}$ versus $0.79 \mathrm{IU} / \mathrm{kg}$ at 13 years). In multivariate regression analysis, ID was significantly $(P>0.001)$ associated with age, gender, and insulin delivery regime.

Conclusion: The ID-Perc were significantly different during various periods of childhood and were influenced by gender, body weight, and insulin injection regimes. Therefore, the presented data 1) provide evidence to interpret individual ID in children and adolescents with DM1 and 2) more specifically identify children with unusually high (insulin resistance and non-compliance) or low (MODY and persistent remission) insulin requirement.
\end{abstract}

European Journal of Endocrinology 158 543-549

\section{Introduction}

The daily insulin dose (ID) is a substantial parameter for the management of type 1 diabetes mellitus (DM1) in children and adolescents (1). A low ID representing underinsulinization could cause symptoms of insulin deficiency $(2,3)$ whereas a high ID could be a sign of insulin resistance $(4,5)$. Both conditions are statistically associated with poor metabolic control. Furthermore, diabetes management might improve if patients with unusually high (non-compliance, insulin resistance) or low (maturity onset of diabetes in the youth (MODY), persistent remission, and type 2 diabetes) insulin requirement could clearly be identified. But until now, there are no age- and gender-specific normative data on daily ID in children and adolescents with type 1 diabetes. Moreover, the decision whether an individual ID is abnormally low or high was difficult, because even pediatric guidelines answer this question only superficially (ISPAD consensus guidelines 2007; www.ispad.org).

Furthermore, childhood and adolescence cover phases of growth and pubertal development with substantial changes of metabolic condition. Especially during puberty, physiological insulin resistance increases to some degree (6). On the other hand, obesity is a rising problem also in children with DM1 and insulin resistance is frequent in those obese children. Some diabetes-related complications, for example, non-alcoholic fatty liver disease (NAFLD) or hyperlipidemia, are known in insulin resistance as well as in insulin deficiency (7). Therefore, it is very 
important for clinical care to classify the ID as low, average, or high in relation to age, gender, body weight (expressed as SDS body mass index $=$ BMISDS), and type of insulin requirement (MIT or CSII) in order to improve the database for the interpretation of the ID. The purpose of this study was to generate representative ID-percentiles (ID-Perc) from a large multicenter cohort of children and adolescents with DM1 and to identify influencing factors.

\section{Subjects and methods}

The study included 22177 children and adolescents between 3 and 23 years of age who had DM1 for at least 2 years. Of them, $48 \%$ were female and $52 \%$ were male. This report summarizes the data of 222 pediatric diabetes centers in Germany and Austria accumulated in 1995 to March 2006. A computer software based on the FoxPro 9.0 compiler was developed for standardized prospective documentation of children and adolescents with diabetes (Diabetes Patienten Verlaufsdokumentation system) (8). Besides anthropometric parameters, ID per day, metabolic control (HbA1c), and treatment modalities are documented longitudinally by the software. The software allows standardized patient reports as well as local aggregation of data and patient selection according to multiple criteria. Anonymized data are transmitted for central multicenter analysis. Each participating center complies with their local ethical and data management guidelines. Inconsistent data were reported back to the centers twice a year for correction.

\section{ID and insulin injection regime}

ID was documented at each appointment as the dispenser dose over a period of 1 week excluding times with acute infections or unusual activities or circumstances (sport camps and fasting situation). The ID was expressed as IU/kg body weight. In patients with MIT, the number of insulin injections, the dosage and the type of insulin were reported. In patients with CSII, the basal rate and the daily sum of all boli was used to calculate ID.

\section{Body weight}

Body weight was recorded as BMI and the BMI-SDS using the LMS method (9): the median (M) and the coefficient of variation (S) of BMI for German children at each age and gender, whereas the lambda for the skew (L) value allows for the substantial agedependent skewness in the distribution of BMI (10). Using these references, a BMISDS above 1.9 corresponds to obesity in children and adolescents independent of age or gender.
The ideal body weight (IW) was defined as the weight corresponding to BMISDS of zero based on the height of the child. The ID was correlated to BMISDS and IW and ID-Perc were created with and without adjustment for IW.

\section{Statistical analysis}

The SAS 9.1 statistic software package (SAS Institute Inc., Cary, North Carolina, USA) was used for the descriptive data evaluation. Non-parametric statistical tests (Mann-Whitney U-test/Wilcoxon test) were used. A $P<0.05$ was considered as significant. The ID is presented as median and 5th, 10th, 25th, 75th, 90th, and 95th percentile. The associations of ID with age, gender, type of insulin therapy, and body weight were analyzed by multiple regression analysis with ID and age as the dependent variables, including gender, BMISDS, insulin therapy regimen, and number of insulin injections per day as independent variables in each model in the whole study population, including all children and adolescents irrespective of HbA1c levels. The regression analysis was performed for the third year of diabetes duration, a moment when the residual insulin secretion is no longer relevant.

\section{Results}

\section{ID-Percentiles}

The daily ID percentiles (ID-Perc) are based on 10647 female and 11516 male children and adolescents with DM1, representing 77082 patient years.

Patient characteristics such as the distribution of age, gender, and diabetes duration are presented in Table 1. The ID-Perc for the whole study population showed a minimum ID at 3 years of age $(P 50=0.67 \mathrm{IU} / \mathrm{kg})$, a maximum ID at 13 years of age $(\mathrm{P} 50=0.93 \mathrm{IU} / \mathrm{kg})$, followed by a decrease after puberty at 23 years of age $(\mathrm{P} 50=0.70 \mathrm{IU} / \mathrm{kg})$. The mean ID (P50) varies 31\% over this period of lifetime with a significant increase during puberty (Fig. 1).

ID below the 5 th percentile (P5) is characterized as low insulin dosage, in contrast to ID above the 95th percentile (P95) marked as high insulin dosage.

\section{ID and gender}

Growth pattern and pubertal development differ in boys and girls. Therefore, ID-Perc were created separately for males and females (Fig. 2). The daily ID (IU/kg) is significantly different for boys and girls between 3 and 18 years of age $(P<0.001$; except $P=0.001$ at 4 years and $P=0.01$ at 14 years). The ID is higher in girls at 3-13 years of age and higher in boys at 14-18 years of age. The maximum of P50 is significantly different in boys and girls $(0.92 \mathrm{IU} / \mathrm{kg}$ in male versus $0.94 \mathrm{IU} / \mathrm{kg}$ in 


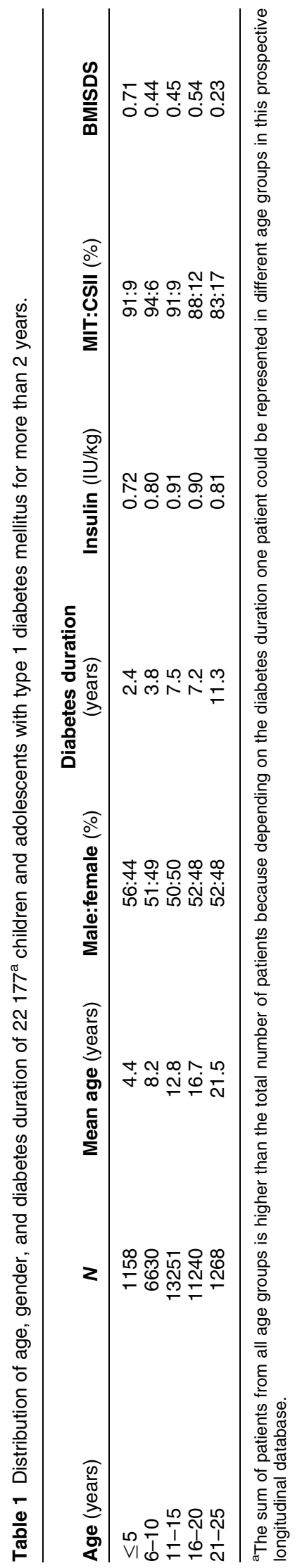

female; $P<0.001$ ) but the maximum of $P 95$ is not $(1.42 \mathrm{IU} / \mathrm{kg}$ in male versus $1.41 \mathrm{IU} / \mathrm{kg}$ in female). The maximum of $\mathrm{P} 50$ and $\mathrm{P} 95$ is reached in girls at 12 years of age compared with boys at 14 years of age.

\section{ID and BMI}

In the third year of diabetes duration, obesity in children and adolescents with DM1 (BMISDS $>1.9$ ) does not significantly increase ID. In contrast, obese children with DM1 need a significantly lower ID per kg body weight and BMISDS $>1.9$ had a negative effect in the regression analysis $(e=-0.085 ; P<0.001)$.

\section{ID and insulin injection regimes}

ID is significantly different in patients with multiple insulin injection therapy (MIT) compared with patients with continuous s.c. insulin infusion (CSII; Fig. 3) between 4 and 22 years of age $(P<0.001)$. P50 for CSII is consistently lower than for MIT. Regarding P95, the range is wide but at $3-5$ years of age P95 is even higher in CSII than in MIT.

\section{Multivariate analysis}

Associations among ID, age, BMISDS, and number of daily insulin injections ID per weight and per IW were significantly influenced by age, gender, degree of obesity, insulin injection regimen, and number of insulin injections per day using multivariate linear regression analyses. In these multivariate models, increased BMISDS was associated with a decrease in ID per $\mathrm{kg}$ weight (see above).

The influence of body weight on ID was tested by recalculating the daily ID not by per kg body weight, but by per kg ideal body weight (IW). The ID was now significantly higher (e.g., P50 at 13 years $0.91 \mathrm{IU} / \mathrm{kg}$ IW versus $0.99 \mathrm{IU} / \mathrm{kg} ; \quad P<0.001$ ) and significantly different for boys and girls between 3 and 14 years of age (e.g., $\mathrm{P} 50$ at 13 years $\delta^{\dagger}=0.96 \mathrm{IU} / \mathrm{kg} \mathrm{IW}$ versus $q=$ $1.02 \mathrm{IU} / \mathrm{kg} \mathrm{IW} ; P<0.001$ ), but the ID was higher in females throughout the whole period.

\section{Discussion}

Daily IDs used for the treatment of DM1 vary remarkably during childhood and adolescence (11). Therefore, age- and gender-specific ID-Perc based on 77094 patient years were created. The study population was not separated into good or insufficient metabolic control to avoid a systemic bias. The aim was to offer more reliable interpretation of the individual ID for health care professionals in the management of juvenile type 1 diabetes $(12,13)$. 


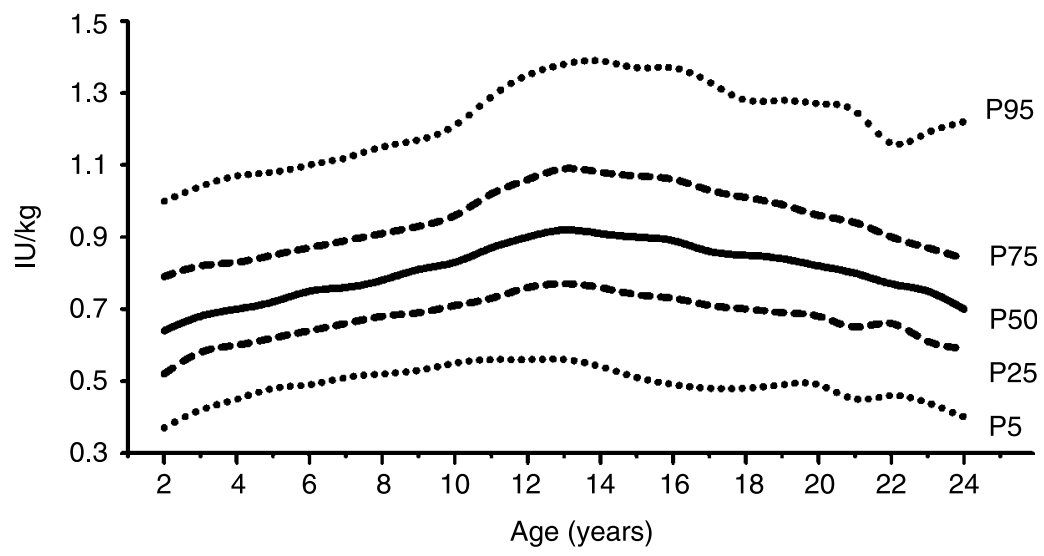

Figure 1 Insulin requirement per kilogram body weight and day $(\mathrm{IU} / \mathrm{kg})$ : all patients; diabetes duration $>2$ years; 5 th, 25th, 50 th, 75th, and 95th percentile.
Potential explanations for abnormal insulin requirement are variable. Also diabetes of non-autoimmune origin should be considered if ID is unexpectedly low. In patients with autoantibody negative type $1 \mathrm{~B}$ diabetes and autosomal dominant inheritance of diabetes, molecular genetic testing for MODY should be considered (14). Furthermore, associated autoimmune diseases in terms of adrenocortical insufficiency (Addison's disease) often results in decreasing insulin requirement and hypoglycemia in children and adolescents with DM1. Although rare in the general population, it is more common in patients with DM1. The combination of Addison's disease with DM1 and/or autoimmune thyroid disease is known as autoimmune polyendocrine syndrome type 2 . In addition to the 'classic' Addisonian features, the development of unexplained recurrent hypoglycemia, reduction in total insulin requirement, improvement in glycemic control, or abnormal pigmentation should arouse suspicion of adrenocortical insufficiency (15). Insulin withdrawal with the intention to manipulate weight is a first sign of eating disorders, especially in adolescent and young adult female subjects with DM1 (16, 17). Decreasing insulin requirement might be the first sign of anorectic behavior, even before weight loss is evident. Furthermore, normalization of insulin amounts might be another target next to BMI, to control efficiency of psychotherapy in patients with anorexia nervosa. Age-specific ID-Perc are helpful to define expected insulin requirements.

Insulin deficiency invariably results in impaired metabolic control $(18,19)$. Cardiovascular risk factors such as obesity, hypertension, dyslipidemia, and smoking were associated with poor glycemic control analyzed in 27358 children and adolescents with DM1 (20). The long-term consequences and complications are well known even in adolescents with DM1: beginning in microangiopathy resulting in diabetic retinopathy, nephropathy, and neuropathy $(21,22)$ and also growth retardation (23), liver disease, and dyslipidemia (24) (Mauriac syndrome). Insulin deficiency defined as a daily ID below the 5 th percentile, results in cut off values between 0.34 ( 02 years of age) and $0.58 \mathrm{IU} / \mathrm{kg}$ per day ( +12 years of age). This wide range is partly due to the difference in insulin sensitivity in relation to age and especially in relation to puberty (25-27). It may also reflect more careful adaptation of the ID in younger children since blood glucose fluctuations are very frequent in preschool children and hypoglycemia awareness is difficult (28-30).

Insulin requirement analyzed in this study is based on the information provided by the patients/families. This applies to our study as well as all other reports in the literature on insulin requirement in outpatients with

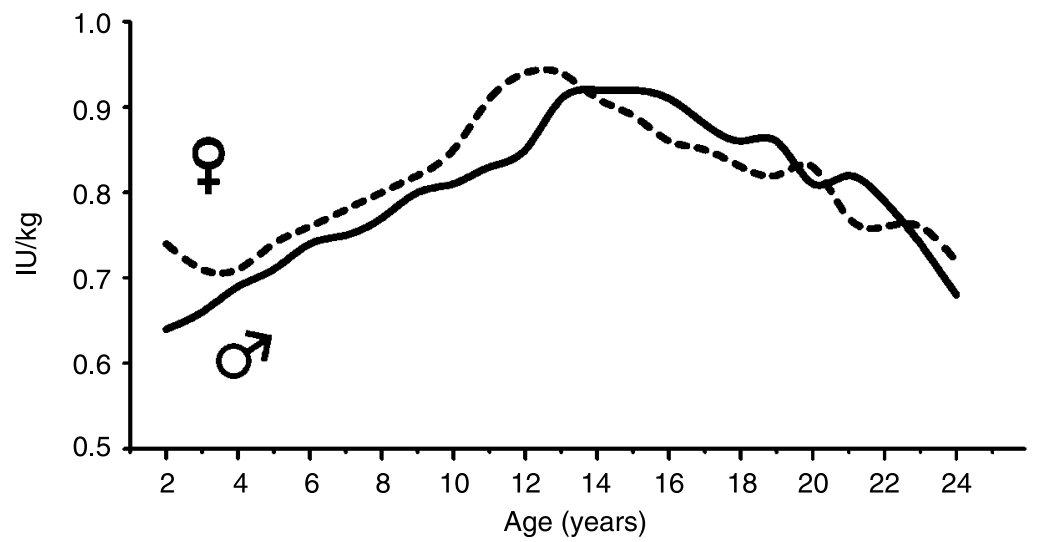

Figure 2 Median insulin requirement (IU, insulin per kilogram body weight and day): separated for males (solid line) and females (dashed line).

www.eje-online.org 


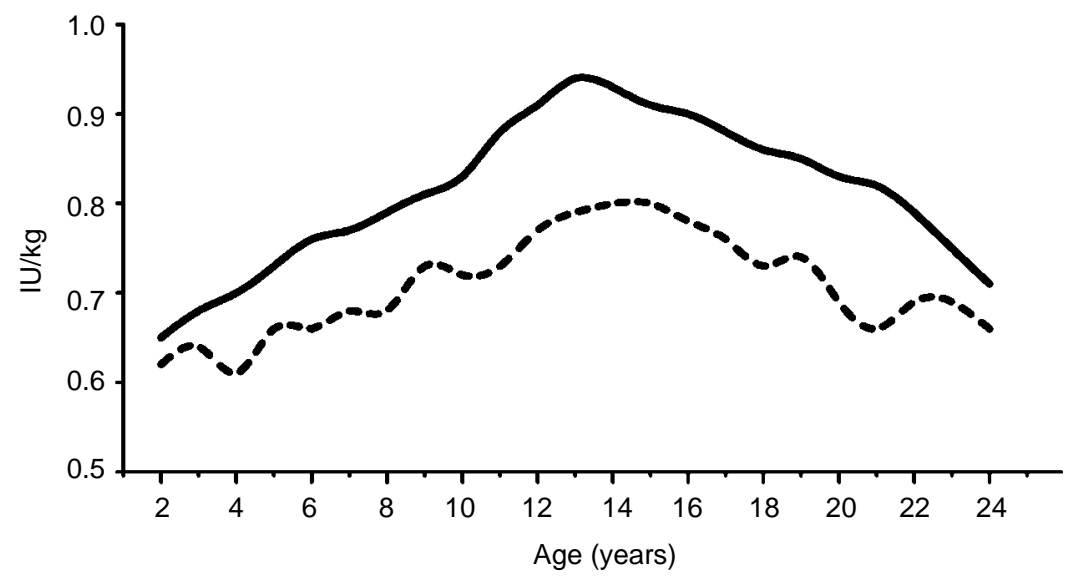

Figure 3 Median insulin requirement (IU, insulin per kilogram body weight and day): separated for insulin injection therapy (solid line) and continuous s.c. insulin infusion (dashed line). any form of diabetes. Reported IDs are the basis for suggested dose adjustments during outpatient visits. Under special psychosocial circumstances, reported IDs may systematically differ from actually administered IDs. Insulin purging is a phenomenon that sometimes occurs in teenage girls with type 1 diabetes trying to loose weight. However, in this situation, actually applied IDs are clearly not reflecting insulin requirements for age. Furthermore, fasting hypoglycemia and postprandial hyperglycemia could be incurred when insulin antibodies with strong affinity and high capacity in high-affinity sites arise (31).

To the contrary, overinsulinization and insulin resistance might be assumed, if the ID is above the 95th percentile. Potential underlying causes are related to the physiology of puberty (32-34) but furthermore, insulin resistance per se might aggravate pathophysiology of autoimmune $\beta$-cell destruction and accelerate progression to overt type 1 diabetes (35-37). As known from patients with type 2 diabetes, patients with type 1 diabetes display insulin resistance and high insulin requirement in relation to obesity and low physical activity (38-41). On the other hand, treatment strategies in children and adolescents with type 1 diabetes changed rapidly within the last decade also in regards to nutritional recommendations. Introduction of MIT regimens enabled a liberalization of carbohydrate intake under the label of 'free eating' $(42,43)$. But as a consequence, consumption of carbohydrate-rich soft drinks and ordinary sweets raised ID significantly in individual patients.

A treatment option in adolescents with type 1 diabetes and high ID might be the addition of metformin. In a double-blind placebo-controlled trial with 30 randomized adolescents with type 1 diabetes, metabolic control and insulin sensitivity improve significantly (44).

Insulin resistance is physiological during puberty to some extent, for example, to reduce the protein consumption and parallel shift this amount into anabolic effect and growth (45). Serum insulin levels in non-diabetic girls and boys are closely related to clinical stages of puberty, with parallel relationships to androgens or adiponectin (46). Furthermore, there is some evidence for menstrual cycle effects on insulin sensitivity (47). Unfortunately, in our multicenter study, cohort Tanner stages are not documented systematically in all patients, as some physicians believe that routine physical examination undressing the patient disrupts a non-hierarchical patient-doctor communication. Therefore, the ID has not been correlated to pubertal stages, but peak levels of ID at 12 years in girls and 14 years in boys strongly suggest a relation to pubertal development.

Insulin resistance is related to obesity. Therefore, the ID was adjusted and recalculated in relation to ideal body weight' (BMISDS=0). Using this method, the maximum ID is not only significantly earlier but also higher in girls than in boys mirroring the higher prevalence of overweight and obesity in girls with DM1 especially around puberty (data not shown). In contrast, the negative effect of obesity in the multivariate linear regression analyses on ID contradicts the hypothesis that obesity in children and adolescents with type 1 diabetes additionally influences the insulin requirement (35). Possible explanations for this observation include the relatively low insulin concentration in the portal vein compared with peripheral insulin levels due to s.c. insulin injection, or altered body composition due to anabolic insulin effects on muscle tissue.

It is well known that different insulin application forms result in different ID $(48,49)$. CSII could deliver fasting and prandial insulin in a more physiological fashion than MIT. Therefore, the ID is significantly lower in CSII than in MIT (50) except for children at preschool age. This finding is due to a different indication for CSII in preschool children compared with older children and adolescents (51). Since CSII is difficult to supervise in very young children, it is usually a poor metabolic control indication with unsuccessful trial of any other therapeutic regimens $(52,53)$. 
In summary, these detailed percentiles of daily insulin requirement in children and adolescents with type 1 diabetes will support clinical experience to adjust treatment regimens, providing objective data to enable diabetes care professionals in the interpretation of individual insulin requirements. In addition, differential diagnoses to other types of diabetes will be facilitated and objective evidence for prospective clinical trials is provided.

\section{Acknowledgements}

This study received financial support from the German Ministry of Health, German Diabetes Association, German Research Foundation (DFG), National Action Forum DM (NAFDM), German Diabetes Foundation, Dr Bürger-Büsing Foundation, and Novo Nordisk Germany. There is no conflict of interest to declare.

\section{References}

1 Holl RW, Swift PG, Mortensen HB, Lynggaard H, Hougaard P, Aanstoot HJ, Chiarelli F, Daneman D, Danne T, Dorchy H, Garandeau P, Greene S, Hoey HM, Kaprio EA, Kocova M, Martul P, Matsuura N, Robertson KJ, Schoenle EJ, Sovik O, Tsou RM, Vanelli M \& Aman J. Insulin injection regimens and metabolic control in an international survey of adolescents with type 1 diabetes over 3 years: results from the Hvidore study group. European Journal of Pediatrics 2003162 22-29.

2 Morris AD, Boyle DI, McMahon AD, Greene SA, MacDonald TM \& Newton RW. Adherence to insulin treatment, glycaemic control, and ketoacidosis in insulin-dependent diabetes mellitus. The DARTS/MEMO Collaboration. Diabetes Audit and Research in Tayside Scotland. Medicines Monitoring Unit. Lancet 1997350 1505-1510.

3 Wagner VM, Grabert M \& Holl RW. Severe hypoglycaemia, metabolic control and diabetes management in children with type 1 diabetes in the decade after the Diabetes Control and Complications Trial - a large-scale multicentre study. European Journal of Pediatrics $200516 \mathbf{1 3}$ 73-79.

4 De Fronzo RA, Hendler R \& Simonson D. Insulin resistance is a prominent feature of insulin-dependent diabetes. Diabetes 198231 795-801.

5 Teupe B \& Bergis K. Epidemiological evidence for 'double diabetes'. Lancet 1991337 361-362.

6 Allard P, Delvin EE, Paradis G, Hanley JA, O'Loughlin J, Lavallee C, Levy E \& Lambert M. Distribution of fasting plasma insulin, free fatty acids, and glucose concentrations and of homeostasis model assessment of insulin resistance in a representative sample of Quebec children and adolescents. Clinical Chemistry 200349 644-649.

7 Wiltshire EJ, Hirte C \& Couper JJ. Dietary fats do not contribute to hyperlipidemia in children and adolescents with type 1 diabetes. Diabetes Care 200326 1356-1361.

8 Holl RW \& Grabert M. The quality circle: how to improve the outcome of paediatric diabetes care. Hormone Research 200357 105-109.

9 Cole TJ, Bellizzi MC, Flegal KM \& Dietz WH. Establishing a standard definition for child overweight and obesity worldwide: international survey. BMJ $2000 \mathbf{3 2 0} 1240-1243$.

10 Kromeyer-Hauschild K, Wabitsch M, Geller F, Ziegler A, Geiß HC, Hesse V, v Hippel V, Jaeger U, Johnsen D, Müller G, Korte W, Kunze D, Menner K, Müller M, Niemann-Pilatus A, Remer T, Schaefer F, Wittchen HU, Zabransky S, Zellner K \& Hebebrand J.
Percentiles of body mass index in children and adolescents evaluated from different regional German studies. Monatsschrift für Kinderheilkunde 2001149 807-818.

11 Kerouz N, el-Hayek R, Langhough R \& MacDonald MJ. Insulin doses in children using conventional therapy for insulin dependent diabetes. Diabetes Research and Clinical Practice 199529 113-120.

12 Silverstein J, Klingensmith G, Copeland K, Plotnick L, Kaufman F, Laffel L, Deeb L, Grey M, Anderson B, Holzmeister LA \& Clark N. American Diabetes Association. Care of children and adolescents with type 1 diabetes: a statement of the American Diabetes Association. Diabetes Care 200528 186-212.

13 Bangstad HJ, Danne T, Deeb LC, Jarosz-Chobot P, Urakami T \& Hanas R. International Society for Pediatric and Adolescent Diabetes (ISPAD). Insulin treatment. ISPAD clinical practice consensus guidelines 2006-2007. Pediatric Diabetes 2007 8 88-102.

14 Stride A \& Hattersley AT. Different genes, different diabetes: lessons from maturity-onset diabetes of the youth. Annals of Medicine 2002 34 207-216.

15 Thomas JB, Petrovsky N \& Ambler GR. Addison's disease presenting in four adolescents with type 1 diabetes. Pediatric Diabetes 20045 207-211.

16 Peveler RC, Bryden KS, Neil HA, Fairburn CG, Mayou RA, Dunger DB \& Turner HM. The relationship of disordered eating habits and attitudes to clinical outcomes in young adult females with type 1 diabetes. Diabetes Care 200528 84-88.

17 Iafusco D, Vanelli M, Gugliotta M, Iovane B, Chiari G \& Prisco F. Prevalence of eating disorders in young patients with type 1 diabetes from two different Italian cities. Diabetes Care 2004272278.

18 Rewers A, Chase HP, Mackenzie T, Walravens P, Roback M, Rewers M, Hamman RF \& Klingensmith G. Predictors of acute complications in children with type 1 diabetes. Journal of the American Medical Association 2002287 2511-2518.

19 Holl RW, Swift PG, Mortensen HB, Lynggaard H, Hougaard P, Aanstoot HJ, Chiarelli F, Daneman D, Danne T, Dorchy H, Garandeau P, Greene S, Hoey HM, Kaprio EA, Kocova M, Martul P, Matsuura N, Robertson KJ, Schoenle EJ, Sovik O, Tsou RM, Vanelli M \& Aman J. Insulin injection regimens and metabolic control in an international survey of adolescents with type 1 diabetes over 3 years: results from the Hvidore study group. European Journal of Pediatrics 2003162 22-29.

20 Schwab KO, Doerfer J, Hecker W, Grulich-Henn J, Wiemann D, Kordonouri O, Beyer P \& Holl RW. DPV Initiative of the German Working Group for Pediatric Diabetology. Spectrum and prevalence of atherogenic risk factors in 27358 children, adolescents, and young adults with type 1 diabetes: cross-sectional data from the German diabetes documentation and quality management system (DPV). Diabetes Care 200629 218-225.

21 Nordwall M, Hyllienmark L \& Ludvigsson J. Early diabetic complications in a population of young patients with type 1 diabetes mellitus despite intensive treatment. Journal of Pediatric Endocrinology and Metabolism 200619 45-54.

22 Nathan DM, Cleary PA, Backlund JY, Genuth SM, Lachin JM, Orchard TJ, Raskin P \& Zinman B. Diabetes Control and Complications Trial/Epidemiology of Diabetes Interventions and Complications (DCCT/EDIC) Study Research Group. Intensive diabetes treatment and cardiovascular disease in patients with type 1 diabetes. New England Journal of Medicine 2005353 2643-2653.

23 Chiarelli F, Giannini C \& Mohn A. Growth, growth factors and diabetes. European Journal of Endocrinology 2004151 U109-U117.

24 Van Steenbergen W \& Lanckmans S. Liver disturbances in obesity and diabetes mellitus. International Journal of Obesity and Related Metabolic Disorders 199519 S27-S36.

25 Greenbaum CJ. Insulin resistance in type 1 diabetes. Diabetes/ Metabolism Research and Reviews 200218 192-200.

26 Soliman AT, Omar M, Assem HM, Nasr IS, Rizk MM, El Matary W \& El Alaily RK. Serum leptin concentrations in children with type 1 diabetes mellitus: relationship to body mass index, insulin dose, and glycemic control. Metabolism $200251292-296$.

27 Kiess W, Anil M, Blum WF, Englaro P, Juul A, Attanasio A, Dotsch J \& Rascher W. Serum leptin levels in children and adolescents with 
insulin-dependent diabetes mellitus in relation to metabolic control and body mass index. European Journal of Endocrinology 1998138 501-509.

28 Mortensen HB \& Hougaard P. Comparison of metabolic control in a cross-sectional study of 2873 children and adolescents with IDDM from 18 countries. The Hvidore Study Group on Childhood Diabetes. Diabetes Care 199720 714-720.

29 Herbst A, Roth CL, Dost AG, Fimmers R \& Holl RW. Rate of hypoglycaemia and insulin dosage in children during the initial therapy of type 1 diabetes mellitus. European Journal of Pediatrics $2005164633-638$.

30 Kaufman FR. Intensive management of type 1 diabetes in young children. Lancet 2005365 737-738.

31 Koyama R, Nakanishi K, Kato M, Yamashita S, Kuwahara H \& Katori H. Hypoglycemia and hyperglycemia due to insulin antibodies against therapeutic human insulin: treatment with double filtration plasmapheresis and prednisolone. American Journal of the Medical Sciences 2005329 259-264.

32 Artz E \& Freemark M. The pathogenesis of insulin resistance in children: metabolic complications and the roles of diet, exercise and pharmacotherapy in the prevention of type 2 diabetes. Pediatric Endocrinology Reviews $20041296-309$.

33 Weiss R \& Caprio S. Altered glucose metabolism in obese youth. Pediatric Endocrinology Reviews 20063 233-238.

34 Barker DJ. The developmental origins of insulin resistance. Hormone Research 200564 2-7.

35 Fourlanos S, Narendran P, Byrnes GB, Colman PG \& Harrison LC. Insulin resistance is a risk factor for progression to type 1 diabetes. Diabetologia 200447 1661-1667.

36 Reinehr T, Holl RW, Roth CL, Wiesel T, Stachow R, Wabitsch M \& Andler W. DPV-Wiss Study Group. Insulin resistance in children and adolescents with type 1 diabetes mellitus: relation to obesity. Pediatric Diabetes 20056 5-12.

37 Wilkin T. Is the 'Accelerator hypothesis' worthy of our attention? Diabetic Medicine 200522 1458-1459.

38 Wiegand S, Maikowski U, Blankenstein O, Biebermann $\mathrm{H}$, Tarnow P \& Gruters A. Type 2 diabetes and impaired glucose tolerance in European children and adolescents with obesity a problem that is no longer restricted to minority groups. European Journal of Endocrinology 2004151 199-206.

39 Wiegand S, Dannemann A, Krude H \& Gruters A. Impaired glucose tolerance and type 2 diabetes mellitus: a new field for pediatrics in Europe. International Journal of Obesity 2005 29 S136-S142.

40 Bloomgarden ZT. Aspects of type 2 diabetes and related insulinresistant states. Diabetes Care 200629 732-740.

41 Druet C, Tubiana-Rufi N, Chevenne D, Rigal O, Polak M \& LevyMarchal C. Characterization of insulin secretion and resistance in type 2 diabetes of adolescents. Journal of Clinical Endocrinology and Metabolism 200691 401-404.
42 Holl RW, Grabert M, Sorgo W, Heinze E \& Debatin KM. Contributions of age, gender and insulin administration to weight gain in subjects with IDDM. Diabetologia 199841 542-547.

43 Dabadghao P, Vidmar S \& Cameron FJ. Deteriorating diabetic control through adolescence-do the origins lie in childhood? Diabetic Medicine 2001 18 889-894.

44 Sarnblad S, Kroon M \& Aman J. Metformin as additional therapy in adolescents with poorly controlled type 1 diabetes: randomised placebo-controlled trial with aspects on insulin sensitivity. European Journal of Endocrinology 2003149 323-329.

45 Caprio S, Cline G, Boulware S, Permanente C, Shulman GI, Sherwin RS \& Tamborlane WV. Effects of puberty and diabetes on metabolism of insulin-sensitive fuels. American Journal of Physiology 1994266 E885-E891.

46 Bottner A, Kratzsch J, Müller G, Kapellen TM, Bluher S, Keller E, Bluher M \& Kiess W. Gender differences of adiponectin levels develop during the progression of puberty and are related to serum androgen levels. Journal of Clinical Endocrinology and Metabolism 200489 4053-4061.

47 Trout KK, Rickels MR, Schutta MH, Petrova M, Freeman EW, Tkacs NC \& Teff KL. Menstrual cycle effects on insulin sensitivity in women with type 1 diabetes: a pilot study. Diabetes Technology and Therapeutics 20079 176-182.

48 Williams RM \& Dunger DB. Insulin treatment in children and adolescents. Acta Paediatrica 200493 440-446.

49 Daneman D. Type 1 diabetes. Lancet 2006367 847-858.

50 Doyle EA, Weinzimer SA, Steffen AT, Ahern JA, Vincent M \& Tamborlane WV. A randomized, prospective trial comparing the efficacy of continuous subcutaneous insulin infusion with multiple daily injections using insulin glargine. Diabetes Care 2004 27 1554-1558.

51 Litton J, Rice A, Friedman N, Oden J, Lee MM \& Freemark M. Insulin pump therapy in toddlers and preschool children with type 1 diabetes mellitus. Journal of Pediatrics $2002141490-495$.

52 Berhe T, Postellon D, Wilson B \& Stone R. Feasibility and safety of insulin pump therapy in children aged 2 to 7 years with type 1 diabetes: a retrospective study. Pediatrics 2006 117 2132-2137.

53 Weinzimer SA, Swan KL, Sikes KA \& Ahern JH. Emerging evidence for the use of insulin pump therapy in infants, toddlers, and preschool-aged children with type 1 diabetes. Pediatric Diabetes 20067 15-19.

Received 28 December 2007

Accepted 13 January 2008 